\title{
A didática e a aprendizagem do pensar e do aprender: a Teoria Histórico-cultural da Atividade e a contribuição de Vasili Davydov
}

\author{
José Carlos Libâneo*
}

Universidade Católica de Goiás

Os desafios da escola e da didática atual

e a contribuição da Teoria Histórico-social da Atividade

Ante as necessidades educativas presentes, a escola continua sendo lugar de mediação cultural, e a pedagogia, ao viabilizar a educação, constitui-se como prática cultural intencional de produção e internalização de significados para, de certa forma, promover o desenvolvimento cognitivo, afetivo e moral dos indivíduos. O modus faciendi dessa mediação cultural, pelo trabalho dos professores, é o provimento aos alunos dos meios de aquisição de conceitos científicos e de desenvolvimento das capacidades cognitivas e operativas, dois elementos da aprendizagem escolar interligados e indissociáveis.

* O autor agradece a contribuição do professor Seth Chaiklin no esclarecimento de expressões e termos de difícil compreensão ou interpretação, encontrados na versão em inglês do texto de V. V. Davydov, utilizado como base deste artigo.
Com efeito, as crianças e jovens vão à escola para aprender cultura e internalizar os meios cognitivos de compreender e transformar o mundo. Para isso, é necessário pensar - estimular a capacidade de raciocínio e julgamento, melhorar a capacidade reflexiva e desenvolver as competências do pensar. A didática tem o compromisso com a busca da qualidade cognitiva das aprendizagens, esta, por sua vez, associada à aprendizagem do pensar. Cabe-lhe investigar como ajudar os alunos a se constituírem como sujeitos pensantes e críticos, capazes de pensar e lidar com conceitos, argumentar, resolver problemas, diante de dilemas e problemas da vida prática. A razão pedagógica está também associada, inerentemente, a um valor intrínseco, que é a formação humana, visando a ajudar os outros a se educarem, a serem pessoas dignas, justas, cultas, aptas a participar ativa e criticamente na vida social, política, profissional e cultural.

Este texto apóia-se em duas crenças: uma, que a escola continua sendo uma instância necessária de democratização intelectual e política; outra, que uma política educacional inclusiva deve estar fundamentada na idéia de que o elemento nuclear da escola é a 
atividade de aprendizagem, lastreada no pensamento teórico, associada aos motivos dos alunos, sem o que as escolas não seriam verdadeiramente inclusivas.

Estudos recentes sobre os processos do pensar e do aprender, para além da acentuação do papel ativo dos sujeitos na aprendizagem, insistem na necessidade dos sujeitos desenvolverem competências e habilidades cognitivas. Para Castells (apud Hargreaves, 2001, p. 16), a tarefa das escolas e dos processos educativos é desenvolver em quem está aprendendo a capacidade de aprender, em razão de exigências postas pelo volume crescente de dados acessíveis na sociedade e nas redes informacionais, da necessidade de lidar com um mundo diferente e, também, de educar a juventude em valores e ajudá-la a construir personalidades flexíveis e eticamente ancoradas. Também Morin (2000) expressa com muita convicção a exigência de se desenvolver uma inteligência geral que saiba discernir o contexto, o global, o multidimensional, a interação complexa dos elementos. Ele escreve:

[...] o desenvolvimento de aptidões gerais da mente permite melhor desenvolvimento das competências particulares ou especializadas. Quanto mais poderosa é a inteligência geral, maior é sua faculdade de tratar problemas especiais. A compreensão dos dados particulares também necessita da ativação da inteligência geral, que opera e organiza a mobilização dos conhecimentos de conjunto em cada caso particular. [...] Dessa maneira, há correlação entre a mobilização dos conhecimentos de conjunto e a ativação da inteligência geral. (Morin, 2000, p. 39)

Outros estudos vêm mostrando o impacto dos meios de comunicação na configuração dos modos de pensar e das práticas sociais da juventude (por exemplo, Porto, 2003; Belloni, 2002; Engestrõm, 2002), das tecnologias e dos meios informacionais, dos crescentes processos de diversificação cultural, afetando os processos de ensino e aprendizagem.

É em razão dessas demandas que a didática precisa incorporar as investigações mais recentes sobre modos de aprender e ensinar e sobre o papel mediador do professor na preparação dos alunos para o pen- sar. Mais precisamente, será fundamental entender que o conhecimento supõe o desenvolvimento do pensamento e que desenvolver o pensamento supõe metodologia e procedimentos sistemáticos do pensar. Nesse caso, a característica mais destacada do trabalho do professor é a mediação docente pela qual ele se põe entre o aluno e o conhecimento para possibilitar as condições e os meios de aprendizagem, ou seja, as mediações cognitivas.

O suporte teórico de partida é o princípio vygotskiano de que a aprendizagem é uma articulação de processos externos e internos, visando a internalização de signos culturais pelo indivíduo, o que gera uma qualidade auto-reguladora às ações e ao comportamento dos indivíduos. Esta formulação realça a atividade sócio-histórica e coletiva dos indivíduos na formação das funções mentais superiores, portanto o caráter de mediação cultural do processo do conhecimento e, ao mesmo tempo, a atividade individual de aprendizagem pela qual o indivíduo se apropria da experiência sociocultural como ser ativo. Todavia, considerando-se que os saberes e instrumentos cognitivos se constituem nas relações intersubjetivas, sua apropriação implica a interação com os outros já portadores desses saberes e instrumentos. Em razão disso é que a educação e o ensino se constituem formas universais e necessárias do desenvolvimento mental, em cujo processo se ligam os fatores socioculturais e as condições internas dos indivíduos.

O que está em questão é como o ensino pode impulsionar o desenvolvimento das competências cognitivas mediante a formação de conceitos e desenvolvimento do pensamento teórico, e por quais meios os alunos podem melhorar e potencializar sua aprendizagem. Em outras palavras, trata-se de saber o que e como fazer para estimular as capacidades investigadoras dos alunos, ajudando-os a desenvolver competências e habilidades mentais. Em razão disso, uma didática a serviço de uma pedagogia voltada para a formação de sujeitos pensantes e críticos deverá salientar em suas investigações as estratégias pelas quais os alunos aprendem a internalizar conceitos, competências e habilidades do pensar, modos de ação 
que se constituam em "instrumentalidades" para lidar praticamente com a realidade: resolver problemas, enfrentar dilemas, tomar decisões, formular estratégias de ação. Davydov ${ }^{1}$ explicita seu entendimento dessas questões:

O saber contemporâneo pressupõe que o homem domine o processo de origem e desenvolvimento das coisas mediante o pensamento teórico, que estuda e descreve a lógica dialética. O pensamento teórico tem seus tipos específicos de generalização e abstração, seus procedimentos de formação dos conceitos e operações com eles. Justamente, a formação de tais conceitos abre aos escolares o caminho para dominar os fundamentos da cultura teórica atual. [...] A escola, a nosso juízo, deve ensinar as crianças a pensar teoricamente. (apud Golder, 2002, p. 49)

O objetivo deste estudo é, assim, explorar as contribuições teóricas da Teoria Histórico-cultural da Atividade, especialmente a Teoria do Ensino Desenvolvimental de V. Davydov, para as tarefas da didática em relação à aprendizagem do pensar e do aprender.

\section{Breve histórico da Teoria da Atividade e conceitos básicos}

\section{O debate dentro da Escola de Vygotsky}

A Teoria Histórico-cultural da Atividade, desenvolvida inicialmente por Leontiev, Rubinstein e Luria, é geralmente considerada uma continuidade da escola histórico-cultural iniciada por Vygotsky. Segundo Leontiev, "a idéia da análise da atividade como método na psicologia científica do homem foi formulada nos primeiros trabalhos de L. S. Vygotsky" (1983, p. 82). O conceito de atividade é bastante familiar na tradição da filosofia marxista. A atividade, cuja ex-

1 O nome de Vasili Vasilievich Davydov aparece nas publicações ora como Davydov ora como Davidov. Optei pela primeira forma, Davydov, em virtude de ser essa a grafia utilizada na principal obra consultada para a redação deste texto. pressão maior é o trabalho, é a principal mediação nas relações que os sujeitos estabelecem com o mundo objetivo. Conforme Vygotsky, o surgimento da consciência está relacionado com a atividade prática humana, a consciência é um aspecto da atividade laboral. Escreve Leontiev:

Este enfoque encontrou sua expressão na concepção de atividade psíquica como uma forma peculiar de atividade, como um produto e um derivado da vida material, da vida externa, que se transforma [...] em atividade da consciência. Aqui se põe como tarefa central a investigação da própria estrutura da atividade e sua interiorização. (apud Davydov, 2002) $)^{2}$

Na base da idéia de atividade externa está um princípio central da filosofia materialista dialética: o condicionamento histórico-social do desenvolvimento do psiquismo humano, que se realiza no processo de apropriação da cultura mediante a comunicação com outras pessoas. Tais processos de comunicação e as funções psíquicas superiores envolvidas nesses processos se efetivam primeiramente na atividade externa (interpessoal) que, em seguida, é internalizada pela atividade individual, regulada pela consciência. No processo de internalização da atividade há a mediação da linguagem, em que os signos adquirem significado e sentido (Vygotsky, 1984, p. 59-65).

Toda ação humana está orientada para um objeto, de forma que a atividade tem sempre um caráter objetal. O êxito de uma atividade está em estabelecer seu conteúdo objetal. O ensino tem a ver diretamente com isso: é uma forma social de organização da apropriação, pelo homem, das capacidades formadas sócio-historicamente e objetivadas na cultura material e espiritual. Esta apropriação requer comunicação em sua forma externa. Em suas formas iniciais, esta comunicação não está mediatizada pela palavra, mas

2 Neste artigo, todas as citações de obras originalmente escritas em inglês ou espanhol, tal como constam da bibliografia, foram traduzidas pelo autor. 
pelo objeto. "Unicamente sobre a base das ações objetais conjuntas com o adulto, a criança vai dominando a linguagem, a comunicação verbal" (Davydov, 2002, p. 57). Mas para que isso aconteça, é necessário que o sujeito realize determinada atividade, dirigida à apropriação da cultura. Leontiev, citado por Davydov, escreve que a apropriação "é o processo que tem por resultado a reprodução, pelo indivíduo, das capacidades e procedimentos de conduta humanas, historicamente formados" (idem, p. 55). ${ }^{3}$

A cultura desempenha, assim, um papel relevante, por permitir ao ser humano a interiorização dos modos historicamente determinados e culturalmente organizados de operar com informações. Escreve Davydov (1988b):

A apropriação das formas da cultura pelo indivíduo é, a nosso juízo, o caminho já elaborado de desenvolvimento de sua consciência. Aceita esta proposição, a tarefa fundamental da ciência será a de determinar como o conteúdo do desenvolvimento espiritual da humanidade se transforma em suas formas de desenvolvimento espiritual e como a apropriação dessas formas pelo indivíduo se transforma no conteúdo do desenvolvimento de sua consciência. (p. 61)

3 A expressão "atividade reprodutiva" não deve ser interpretada como imitação, repetição, memorização, como na linguagem usual. A atividade, no sentido marxista, nunca seria uma reprodução mecânica de ações. Conforme registra Chaiklin (2003a): "Em suas ações únicas ou singulares, a pessoa reproduz a atividade que organiza suas ações. Leontiev e Davydov utilizam esta expressão para enfatizar que não se trata da criação de uma atividade 'nova', mas de uma 'versão' nova. [...] Penso que 'reprodução' deve ser interpretada aqui para significar que a pessoa recria as práticas humanas historicamente desenvolvidas. Por exemplo, quando alguém aprende aritmética há, até certo ponto, uma reprodução de práticas historicamente desenvolvidas, mesmo que haja pequenas variações em como um indivíduo percebe a prática objetiva”. Poder-se-ia dizer, como Leontiev, que os indivíduos realizam uma atividade prática ou cognoscitiva ou cognitiva adequada à atividade humana precedente encarnada neles.
A atividade, tanto externa como interna, tem uma estrutura psicológica, cujos componentes são: necessidades, motivos, finalidades e condições de realização da finalidade. Ao curso psicológico da atividade corresponde à realização de diversas ações, cada ação composta por uma série de operações em correspondência com as condições peculiares da tarefa, conforme veremos adiante.

Os trabalhos realizados por Leontiev (1903-1979) no período de 1930-1940 foram dedicados à investigação do desenvolvimento do psiquismo humano, dos processos psicológicos superiores, do processo de internalização, da estrutura da atividade global e seu desdobramento em outras atividades, das emoções e dos processos de comunicação. Na seqüência desses estudos, outros pesquisadores dedicaram-se ao desenvolvimento da Teoria da Atividade, entre eles, Galperin (Psicologia Infantil), Bozhovich (Psicologia da Personalidade), Elkonin (Psicologia Evolutiva e periodização do desenvolvimento humano), Zaporoyetz (Psicologia Evolutiva) e Levina (Psicologia da Educação) (cf. Golder, 2002).

Piotr Iakovlevich Galperin (1902-1988) formula a Teoria do Desenvolvimento Psíquico, na qual ressalta o papel das ações externas no surgimento e formação das ações internas, mentais, por meio do ensino. A "teoria por etapas das ações mentais" afirma que a formação da mente deve ser planejada e realizada por meio de uma seqüência de etapas de ações mentais. A formação de uma ação mental começa com ações com objetos, realizadas com o apoio de objetos externos e sua representação material, para logo passar por uma série de etapas até se converter em ação que se realiza no plano mental (Coletivo de Autores, 2000). Daniil B. Elkonin (1904-1984), que exerceu forte influência nas pesquisas de Davydov, destacouse pelas suas pesquisas sobre a periodização do desenvolvimento humano e a aprendizagem escolar. Para ele, a aprendizagem é uma forma essencial de desenvolvimento psíquico e o caminho lógico para analisar capacidades humanas. A aprendizagem conduz ao desenvolvimento através da atividade, tendo-se em conta o papel dos fatores externos do desenvolvimen- 
to, com destaque especial à incorporação da cultura vista em sua formação histórica, não como cultura dada, tema que reaparecerá na obra de Davydov.

Davydov, em texto recente (1999), relata o desenvolvimento da Teoria da Atividade na Rússia nos últimos vinte anos, desde sua formulação inicial por Rubinstein e Leontiev. Destaca a importância das pesquisas do psicólogo finlandês Y. Engestrõm, aponta o trabalho de Elkonin como um dos pioneiros no estudo específico da atividade de aprendizagem e explicita seu próprio entendimento da teoria histórico-cultural da atividade.

A expansão da Teoria da Atividade para o norte da Europa, Estados Unidos e América Latina se dá a partir dos anos de 1960. No norte da Europa são conhecidos os nomes de Yrjo Engestrõm, Seth Chaiklin, Mariane Hedegaard, Jean Lave, entre outros. ${ }^{4}$ Nos Estados Unidos destacam-se diversos especialistas em Vygotsky, tais como Michel Cole, da Universidade da Califórnia, estudioso das relações interpessoais e interculturais na formação da criança, J. Werstsch, Vera John-Steiner, Ellen Souberman, Sylvia Scribner (que organizou com Cole o livro Formação social da mente, publicado no Brasil em 1968) e Louis Moll. Da mesma forma que são encontradas muitas interpretações dentro da psicologia histórico-cultural, também em relação à Teoria da Atividade existem dife-

4 Para um levantamento recente dessas tendências veja-se: S. Chaiklin, M. Hedegaard e U. J. Jensen (orgs.). Activity theory and social practice: cultural-historical approaches [Aarthus (Dinamarca): Aarthus University Press, 1999], que traz textos preparados para o Primeiro Congresso da Sociedade Internacional sobre Teoria da Atividade e Pesquisa Cultural (ISCRAT). O nome dessa sociedade mudou, recentemente, para International Society for Cultural and Activity Research (ISCAR). Na Universidade de Helsinki, há o Centro para Teoria de Atividade e Pesquisa de Trabalho Desenvolvimental, fundado em 1994, atualmente dirigido por um conhecido pesquisador, Yrjo Engestrõm, que realiza pesquisa sobre trabalho, tecnologia e organizações que estão passando por transformações. Para uma boa pesquisa sobre interpretações correntes da Teoria da Atividade, ver Gonzáles Rey (2003). rentes caminhos interpretativos, ainda que os pontos em comum digam respeito aos seus fundamentos epistemológicos, vinculados ao materialismo histórico e dialético.

Os estudos teóricos recentes da Teoria da Atividade têm realçado temas como a atividade situada em contextos, a participação como condição de compreensão na prática (como aprendizagem), identidade, papel das práticas institucionalizadas nos motivos dos alunos, a diversidade cultural etc. Na base do estudo desses temas, há a premissa de que todas as ações individuais devem ser interpretadas tendo em conta questões e fatores que não estão imediatamente presentes na situação, nem contidos exclusivamente nas pessoas que atuam nessas situações. Ou seja, na análise das práticas humanas são destacados os fatores do contexto sócio-histórico em razão de que as práticas humanas são socialmente situadas, sendo estes fatores decisivos nos processos mediacionais, já que eles se realizam na e pela participação em atividades socioculturais (Chaiklin \& Lave, 2001).

Segundo Engestrõm, no processo de evolução da Teoria da Atividade podem ser estabelecidas três gerações. A primeira geração está concentrada nos trabalhos de Vygotsky, quando se formula o conceito da atividade como mediação, gerando o modelo triangular da relação do sujeito com o objetivo mediado por artefatos materiais e culturais; a segunda toma por base a formulação de Leontiev, avançando na distinção, no conceito de atividade, de ação coletiva e ação individual, e estabelecendo a estrutura da atividade; a terceira, proposta pelo próprio Engestrõm a partir dos anos de 1970, parte do modelo triangular de Vygotsky, expandindo-o para um modelo do sistema da atividade coletiva. Neste modelo é realçado o conceito de contradições internas como força motriz dos sistemas de atividade e se introduz as análises da psicologia transcultural de Cole, pelas quais a Teoria da Atividade acolhe as questões da diversidade cultural e do diálogo entre diferentes culturas (cf. Zamberlan, s/d.).

No Brasil, os estudos e pesquisas sobre a teoria de Vygotsky tiveram um desenvolvimento intenso, desde que intelectuais brasileiros tiveram acesso às 
suas obras na segunda metade dos anos de 1980, estando disponível hoje uma vasta bibliografia. São mais raros, todavia, estudos relacionados com a Teoria Histórico-cultural da Atividade e, mais ainda, em relação a Davydov. Em relação à Teoria Históricocultural da Atividade, cumpre destacar os trabalhos de Moura e seus orientandos (Moura, 2003, 2002, 2000; Sforni, 2003). ${ }^{5}$ Numa orientação teoricamente diferenciada em relação à produção mais convencional sobre a psicologia histórico-social estão os trabalhos que Duarte, que tem centrado sua investigação em questões filosóficas e epistemológicas da Teoria Histórico-cultural (por exemplo, 1996, 2003). ${ }^{6}$

5 O Grupo de Estudos sobre Teoria da Atividade, da Faculdade de Educação da Universidade de São Paulo (USP), coordenado pelo professor Manoel Oriosvaldo de Moura, realiza encontros de estudos e debates sobre pesquisas de professores e alunos nessa linha. Registre-se, também, que a Teoria da Atividade, na versão de Leontiev (1983) e seguidores, tem sido largamente utilizada em Cuba por professores dedicados à metodologia do ensino superior, que inclusive a tem difundido em países latino-americanos em cursos de pós-graduação realizados por convênio com instituições universitárias, inclusive brasileiras.

6 Especificamente em relação ao tema deste artigo, Duarte destinou pesadas críticas a trabalhos de autores que, de alguma forma, valorizam o mote do "aprender a aprender" e, com isso, buscam aproximar as idéias vygotskianas das idéias neoliberais e pós-modernas (Duarte, 2000, 2003). Na sua opinião, o “aprender a aprender" leva a uma pedagogia que desvaloriza a transmissão do saber objetivo, dilui o papel da escola em transmitir esse saber, descaracteriza o papel do professor como alguém que detém um saber a ser transmitido para os alunos, negando o próprio ato de ensinar (2000, p. 8). Argumenta que o "aprender a aprender" integra as propostas educacionais neoliberais à medida que atende à formação de indivíduos que possam adaptar-se às atuais formas de trabalho flexível requeridas pelo mercado, isto é, que sejam portadores de conhecimentos meramente técnicos, sem necessidade de domínio dos conhecimentos universais. Com suas próprias palavras, "não se forma indivíduos que sabem algo, que dominam os conhecimentos universais, mas indivíduos predispostos a aprender qualquer coisa, desde que o que se aprende seja útil à
Um trabalho especialmente relevante é o livro de Nereide Saviani, Saber escolar, currículo e didática (1994), que aborda temas como a organização do saber escolar, a relação conteúdo/método, as bases do desenvolvimento cognitivo, aspectos lógicopsicológicos da conversão do saber científico em saber escolar e a unidade entre os campos da didática e do currículo. Em todo o livro há menções a uma obra clássica de Davydov (1978), mas especificamente no capítulo III há uma exposição detalhada de suas idéias sobre o processo de formação de conceitos e formação do pensamento teórico, com base em proposições de Vygotsty e Rubinstein.

As avaliações críticas envolvendo a relação entre a psicologia histórico-cultural e a Teoria da Atividade mostram que há pontos comuns entre os psicólogos russos, mas há também consideráveis divergências, por exemplo, na interpretação da expressão "determinação histórica e social da mente humana" ou do papel da cultura e da linguagem no desenvolvimento humano. Segundo Kozulin, boa parte das divergências giram em torno do problema da internalização e da relação entre a atividade externa da criança e as operações mentais correspondentes. Esta questão, no

adaptação do indivíduo à vida social (i.e., ao mercado) (idem, p. 150). Com base nesse entendimento, conclui que não é possível utilizar a psicologia vygotskiana para legitimar o lema do "aprender a aprender". A meu ver, o entendimento desse autor sobre o "aprender a aprender" está demasiadamente colado a uma conotação política e ideológica, na presunção de que toda visão política produz necessariamente um determinado tipo de didática, ou de que qualquer procedimento didático está necessariamente atrelado a uma determinada visão política. Já dizia, sabiamente, Mario Manacorda, em 1978, que em nenhuma atividade social é possível tomar posição e efetuar opções operacionais somente com base numa orientação ideológica, ou seja, nenhuma concepção de mundo subsiste sem competências específicas em um campo. Diz mais Manacorda: que nem sempre a concepção de mundo e a competência científica nascem sempre e necessariamente na mesma mente, de modo que um grupo social pode apropriar-se da ciência de outro grupo sem aceitar sua ideologia (apud Mariagliano et al., 1986, p. 13). 
período 1934-1940, teria gerado os motivos do distanciamento do grupo liderado por Leontiev em relação às idéias de Vygotsky. Para Leontiev, as operações mentais seriam determinadas pelas relações concretas entre a criança e a realidade, vale dizer, a familiarização prática com os objetos é que leva a criança ao seu desenvolvimento cognitivo (i.e., a estrutura dos processos cognitivos repete a estrutura das operações externas). A relação prática com os objetos, isto é, a atividade prática, teria muito mais importância do que o modelo histórico-cultural desenvolvido por Vygotsky. Vale dizer que, enquanto Leontiev acentuaria a atividade prática, Vygotsky acentuaria a cultura, a linguagem, a mediação simbólica (Kozulin, 2002, p. 125-132).

Essa mesma questão é discutida por Zinchenko, que reconhece a existência de duas linhas de pesquisa dentro da mesma escola: a psicologia históricocultural (Vygotsky) e a Teoria Psicológica da Atividade (Leontiev), com pontos de convergência, mas também com diferenças. Segundo Zinchenko (1998):

A principal diferença é que para a psicologia históricocultural o problema central foi e continua sendo a mediação da mente e da consciência. Para a teoria psicológica da atividade o problema central era a orientação-objeto, em ambas as atividades mentais interna e externa. É claro que na teoria psicológica da atividade a questão mediação também apareceu, mas enquanto que para Vygotsky a consciência era mediada pela cultura, para Leontiev a mente e a consciência eram mediadas por ferramentas e objetos. (p. 44)

Tais diferenças de abordagem, acentuando-se ora o significado ora a ação, ora a atividade orientada a objetos ora o sentido, são, obviamente, de cunho filosófico, gerando diferentes consequiências teóricas e práticas. Zinchenko sugere que se dê continuidade às pesquisas e que olhemos para as duas linhas como complementares, uma se enriquecendo na outra, até que se possa chegar ao desenvolvimento de uma psicologia histórico-cultural da consciência e da atividade.

Também Daniels (2003, p. 93) destaca as semelhanças e diferenças entre duas tradições de investi- gação educacional ligadas historicamente a Vygotsky: a Teoria Sociocultural e a Teoria da Atividade, a primeira focando a mediação semiótica, especialmente a fala, a outra acentuando mais a atividade. Ambas buscam explicar a aprendizagem e o desenvolvimento humano como processos mediados, ambas fornecem orientações metodológicas para captar processos e formas pelos quais fatores sociais, culturais e históricos promovem o desenvolvimento humano, e ambas, especialmente, tratam dos contextos em que ocorrem as mediações cognitivas. Todavia, os procedimentos metodológicos de pesquisa e as aplicações na prática pedagógica tomam caminhos bastante diferentes.

As diferentes interpretações da obra de Vygotsky e seguidores no meio europeu e norte-americano rebatem também no Brasil, assumindo peculiaridades decorrentes das influências teóricas exercidas na investigação educacional e na prática pedagógica.

\section{As contribuições teóricas de Vasili Davydov para a Teoria da Atividade e o ensino desenvolvimental ${ }^{7}$}

Vasili Vasilievich Davydov nasceu em 1930 e morreu em 1998. Membro da Academia de Ciências Pedagógicas, doutor em psicologia, professor universitário, escreveu vários livros, entre eles: Tipos de generalización en la enseñanza, Problemas de la enseñanza y del desarrollo, La enseñanza escolar y el desarrollo psíquico. ${ }^{8}$ Pertence à terceira geração

7 Na versão inglesa do texto de Davydov é utilizada a expressão "developmental teaching", que pode ser traduzida por ensino desenvolvimentalista ou ensino desenvolvimental. Nenhum desses adjetivos é encontrado em português. Optei pela expressão “ensino desenvolvimental", que pode ser descrita nos seguintes termos: o ensino é a forma dominante pela qual se propiciam mudanças qualitativas no desenvolvimento do pensamento.

8 Neste estudo, utilizo mais diretamente a obra Problems of developmental teaching, publicada em três números da revista Soviet Education (Davydov, 1988a, 1988b, 1988c). As citações dessa obra inseridas no texto foram traduzidas pelo autor. Os textos publicados 
de psicólogos russos e soviéticos, desde os trabalhos do grupo inicial de Vygotsky realizados nas décadas de 1920 e 1930.

Conforme vimos, Vygotsky havia mostrado a relevância da escolarização para apropriação dos conceitos científicos e para o desenvolvimento das capacidades de pensamento, a partir da assimilação da produção cultural da humanidade, já que "as funções mentais específicas não são inatas, mas postas como modelos sociais" (Davydov, 1988b, p. 52). Por sua vez, Leontiev investigou os fundamentos do desenvolvimento psíquico humano e sistematizou uma teoria psicológica da atividade e da consciência. A partir dessas bases e de outros estudos conduzidos pela escola de Vygotsky, especialmente de D. Elkonin, Davydov destaca a peculiaridade da atividade da aprendizagem, entre outros tipos de atividade, cujo objetivo é o domínio do conhecimento teórico, ou seja, o domínio de símbolos e instrumentos culturais disponíveis na sociedade, obtido pela aprendizagem de conhecimentos das diversas áreas do conhecimento. Apropriar-se desses conteúdos - das ciências, das artes, da moral significa, em última instância, apropriar-se das formas de desenvolvimento do pensamento. Para isso, o caminho é a generalização conceitual, enquanto conteúdo e instrumento do conhecimento. Ele escreve:

Uma análise da abordagem de Vygotsky e Leontiev sobre o problema do desenvolvimento mental permite que cheguemos às seguintes conclusões. Primeiro, no sentido mais amplo, a educação e o ensino de uma pessoa não são nada mais que sua "apropriação", a "reprodução" por ela das capacidades dadas histórica e socialmente. Segundo, a educação e o ensino ("apropriação") são formas universais de desenvolvimento mental humano. Terceiro, a "apropriação" e o desenvolvimento não podem atuar como dois processos independentes, pois se correlacionam como a forma

nessa revista não correspondem à obra completa publicada originalmente em russo. Todavia, a tradução do inglês foi cotejada com a tradução espanhola da obra original, cujo título é La ensenãnza escolar y el desarrollo psíquico (1988d). e o conteúdo de um único processo de desenvolvimento mental humano. (1988a, p. 54)

A seguir, são apresentados alguns tópicos que buscam trazer uma visão de conjunto do pensamento desse autor.

\section{O conceito psicológico da atividade: a estrutura da atividade}

As bases teóricas que fundamentam os componentes da estrutura da atividade e seu conteúdo foram formuladas por A. N. Leontiev (1983, 1992), mas V. Davydov menciona, também, a contribuição de S. L. Rubinstein e de outros psicólogos que trabalharam nas décadas de 1920-1930. Ele escreve:

A essência do conceito filosófico-psicológico materialista dialético da atividade está em que ele reflete a relação entre o sujeito humano como ser social e a realidade externa - uma relação mediatizada pelo processo de transformação e modificação desta realidade externa. A forma inicial e universal desta relação são as transformações e mudanças instrumentais dirigidas a uma finalidade, realizadas pelo sujeito social, sobre a realidade sensorial e corporal ou sobre a prática humana material produtiva. Ela constitui a atividade laboral criativa realizada pelos seres humanos que, através da história da sociedade, tem propiciado a base sobre a qual surgem e se desenvolvem as diferentes formas da atividade espiritual humana (cognitiva, artística, religiosa etc.). Entretanto, todas estas formas derivadas da atividade estão diretamente ligadas com a transformação, pelo sujeito, de um ou outro objeto sob a forma ideal. O sujeito individual, por meio da apropriação, reproduz em si mesmo as formas histórico-sociais da atividade. [...] A atividade humana tem uma estrutura complexa que inclui componentes como: necessidades percebidas, capacidades, objetivos, tarefas, ações e operações, que estão em permanente estado de interligação e de transformação. (1988a, p. 9)

Conforme Leontiev (1992), a atividade surge de necessidades, que impulsionam motivos orientados 
para um objeto. O ciclo que vai de necessidades a objetos se consuma quando a necessidade é satisfeita, sendo que o objeto da necessidade ou motivo é tanto material quanto ideal. Para que estes objetivos sejam atingidos, são requeridas ações. O objetivo precisa sempre estar de acordo com o motivo geral da atividade, mas são as condições concretas da atividade que determinarão as operações vinculadas a cada ação. Leontiev define como atividade:

[...] aqueles processos que, realizando as relações do homem com o mundo, satisfazem uma necessidade especial correspondente a ele. [...] Por atividade, designamos os processos psicologicamente caracterizados por aquilo que o processo, como um todo, se dirige (i.e., objeto), coincidindo sempre com o objetivo que estimula o sujeito a executar essa atividade, isto é, o motivo. (p. 68)

Há, pois, uma dependência do objetivo em relação ao motivo, ou seja, a atividade implica um sentido. Por sua vez, a ação "é um processo cujo motivo não coincide com seu objetivo, mas reside na atividade da qual faz parte" (ibidem). Conforme explica Leontiev, a atividade de ler o livro somente para passar no exame não é atividade, é uma ação, porque ler o livro por ler não é um objetivo forte que estimula a ação. A atividade é a leitura do livro por si mesmo, por causa do seu conteúdo, ou seja, quando o motivo da atividade passa para o objeto da ação, a ação transforma-se numa atividade. É isso que pode provocar mudanças na atividade principal.

As operações consistem no modo de execução de uma ação, são os conteúdos necessário de qualquer ação, determinada pela natureza da tarefa. Segundo Leontiev, uma mesma ação pode ser efetuada por diferentes operações, mas uma mesma operação também pode realizar diferentes ações, porque uma operação depende das condições em que o alvo da ação é dado, enquanto uma ação é determinada pelo alvo (idem, p. 74). Ele exemplifica essa relação entre ação, tarefa e condições numa situação em que o objetivo é decorar versos. A ação é a memorização dos versos, e para isso posso agir de duas maneiras. Se a pessoa estiver sentada em casa, talvez prefira escrevêlos; em outras condições, poderá recorrer à repetição mental dos versos. Nos dois casos, a ação é a memorização, mas os meios de executá-la, isto é, as operações, serão diferentes.

A atividade humana é global, mas ela se desdobra em distintos tipos concretos de atividade, cuja diferenciação é dada pelo seu conteúdo objetal. Segundo Leontiev, cada tipo de atividade possui um conteúdo perfeitamente definido de necessidades, motivos, tarefas e ações. Por exemplo, o conteúdo objetal da atividade do jogo é substancialmente diferente da atividade de estudo ou da atividade profissional. "O que distingue uma atividade de outra é o objeto da atividade [...] que confere à mesma determinada direção" (Leontiev, 1983, p. 83).

Davydov (1999) concorda com Leontiev sobre o entendimento de que a atividade é constituída de necessidades, tarefas, ações e operações, mas acrescenta um componente que modifica substantivamente a formulação inicial. Trata-se do desejo, enquanto núcleo básico de uma necessidade:

Acredito que o desejo deve ser considerado como um elemento da estrutura da atividade. [...] Necessidades e desejos compõem a base sobre a qual as emoções funcionam. [...] O termo desejo reproduz a verdadeira essência da questão: as emoções são inseparáveis de uma necessidade. [...] Em seus trabalhos, Leontiev afirma que as ações são conectadas às necessidades e motivos. Discordo desta tese. Ações, como formações integrais, podem ser conectadas somente com necessidades baseadas em desejos - e as ações ajudam na realização de certas tarefas a partir dos motivos. [...] É esta a estrutura da atividade que tentei apresentarlhes. [...] Os elementos são os seguintes: desejos, necessidades, emoções, tarefas, ações, motivos para as ações, meios usados para as ações, planos (perceptual, mnemônico, pensamento, criativo) - todos se referindo à cognição e, também, à vontade. (p. 41)

A importância deste ponto de vista é óbvia, pois põe em relevo as relações entre a afetividade e a cognição. A investigação de González Rey (2000) sobre 
a integração do cognitivo e do afetivo na personalidade humana na obra de Vygotsky permite ver aproximações das idéias de Davydov com as de Vygotsky. Escreve esse autor:

Ao outorgar à emoção um status similar ao da cognição, na constituição dos diferentes processos e formas de organização da psique, Vygotsky está sugerindo a independência das emoções, em sua origem, dos processos cognitivos, e integrando as emoções dentro de uma visão complexa da psique que representa um importante antecedente para a construção teórica do tema da subjetividade. (2003, p. 137)

Davydov reforça esta idéia quando escreve que, por detrás das ações humanas estão as necessidades e emoções humanas, antecedendo a ação, as relações com os outros, as linguagens. Isso significa que as ações humanas estão impregnadas de sentidos subjetivos, projetando-se em várias esferas da vida dos sujeitos, obviamente também na atividade dos alunos, na compreensão das disciplinas escolares, no envolvimento com o assunto estudado.

A coisa mais importante na atividade científica não é a reflexão, nem o pensamento, nem a tarefa, mas a esfera das necessidades e emoções. [...] As emoções são muito mais fundamentais do que os pensamentos, elas são a base para todas as diferentes tarefas que um homem estabelece para si mesmo, incluindo as tarefas do pensar. [...] A função geral das emoções é capacitar uma pessoa a pôr-se certas tarefas vitais, mas este é somente meio caminho andado. A coisa mais importante é que as emoções capacitam a pessoa a decidir, desde o início, se, de fato, existem meios físicos, espirituais e morais necessários para que ela consiga atingir seu objetivo. (Davydov, 1999, p. 7)

A relevância das pesquisas de Davydov está precisamente em que, com base na atividade fundamental que é o trabalho, surgem no processo ontogenético outras atividades, entre elas a atividade de aprendizagem. Para ele, a questão central da aprendizagem escolar é o desenvolvimento mental dos alunos por meio do ensino e da educação, que ocorre com a cooperação entre adultos e crianças na atividade de ensino.

\section{O ensino e o desenvolvimento do pensamento:} o ensino desenvolvimental

Na base do pensamento de Davydov está a idéiamestra de Vygotsky de que a aprendizagem e o ensino são formas universais de desenvolvimento mental. O ensino propicia a apropriação da cultura e o desenvolvimento do pensamento, dois processos articulados entre si, formando uma unidade. Podemos expressar essa idéia de duas maneiras: a) enquanto o aluno forma conceitos científicos, incorpora processos de pensamento e vice-versa; b) enquanto forma o pensamento teórico, desenvolve ações mentais, mediante a solução de problemas que suscitam a atividade mental do aluno. Com isso, o aluno assimila o conhecimento teórico e as capacidades e habilidades relacionadas a esse conhecimento.

Para superar a pedagogia tradicional empiricista, é necessário introduzir o pensamento teórico. O papel do ensino é justamente o de propiciar mudanças qualitativas no desenvolvimento do pensamento teórico, que se forma junto com as capacidades e hábitos correspondentes. Em razão disso, escreve Davydov:

Os conhecimentos de um indivíduo e suas ações mentais (abstração, generalização etc.) formam uma unidade. Segundo Rubinstein, “os conhecimentos [...] não surgem dissociados da atividade cognitiva do sujeito e não existem sem referência a ele". Portanto, é legítimo considerar o conhecimento, de um lado, como o resultado das ações mentais que implicitamente abrangem o conhecimento e, de outro, como um processo pelo qual podemos obter esse resultado no qual se expressa o funcionamento das ações mentais. Conseqüentemente, é totalmente aceitável usar o termo "conhecimento" para designar tanto o resultado do pensamento (o reflexo da realidade), quanto o processo pelo qual se obtém esse resultado (ou seja, as ações mentais). "Todo conceito científico é, simultaneamente, uma construção do pensamento $e$ um reflexo do ser". Deste ponto de 
vista, um conceito é, ao mesmo tempo, um reflexo do ser e um procedimento da operação mental. (1988b, p. 21)

Nesse sentido, de um lado, a aprendizagem escolar é estruturada conforme o método de exposição do conhecimento científico, mas, por outro, o pensamento que um aluno desenvolve na atividade de aprendizagem tem algo em comum com o pensamento de cientistas que expõem o resultado de suas pesquisas, quando se utilizam abstrações, generalizações e conceitos teóricos. ${ }^{9}$ Escreve Davydov:

Embora o pensamento das crianças tenha alguns traços em comum com o pensamento dos cientistas, artistas, filósofos da moral e teóricos do direito, os dois não são idênticos. As crianças em idade escolar não criam conceitos, imagens, valores e normas de moralidade social, mas apropriam-se deles no processo da atividade de aprendizagem. Mas, ao realizar esta atividade, as crianças executam ações mentais semelhantes às ações pelas quais estes produtos da cultura espiritual foram historicamente construídos. Em sua atividade de aprendizagem, as crianças reproduzem o processo real pelo qual os indivíduos vêm criando conceitos, imagens, valores e normas. Portanto, o ensino de todas as matérias na escola deve ser estruturado de modo que, como escreveu Ilenkov, "seja reproduzido, de forma condensada e abreviada, o processo histórico real da gênese e desenvolvimento... do conhecimento". (idem, p. 21-22)

As idéias de Davydov sobre o ensino desenvolvimental, lastreadas no pensamento de Vygotsky, podem ser sintetizadas nos seguintes pontos:

9 "Dessa forma, ainda que a atividade de aprendizagem dos escolares se desenvolva em correspondência com o procedimento pelo qual os produtos da cultura espiritual já obtidos são expostos, nesta atividade se conservam, de forma peculiar, as situações e as ações que foram inerentes ao processo de criação real de tais produtos e, por causa disso, o procedimento pelo qual foram obtidos se reproduz de forma abreviada na consciência individual dos escolares" (Davydov, 1988b, p. 23). a) A educação e o ensino são fatores determinantes do desenvolvimento mental, inclusive por poder ir adiante do desenvolvimento real da criança.

b) Deve-se levar em consideração as origens sociais do processo de desenvolvimento, ou seja, o desenvolvimento individual depende do desenvolvimento do coletivo. A atividade cognitiva é inseparável do meio cultural, tendo lugar em um sistema interpessoal de forma que, através das interações com esse meio, os alunos aprendem os instrumentos cognitivos e comunicativos de sua cultura. Isto caracteriza o processo de internalização das funções mentais.

c) A educação é componente da atividade humana orientada para o desenvolvimento do pensamento através da atividade de aprendizagem dos alunos (formação de conceitos teóricos, generalização, análise, síntese, raciocínio teórico, pensamento lógico), desde a escola elementar.

d) A referência básica do processo de ensino são os objetos científicos (os conteúdos), que precisam ser apropriados pelos alunos mediante a descoberta de um princípio interno do objeto e, daí, reconstruído sob forma de conceito teórico na atividade conjunta entre professor e alunos. A interação sujeito-objeto implica o uso de mediações simbólicas (sistemas, esquemas, mapas, modelos, isto é, signos, em sentido amplo) encontradas na cultura e na ciência. A reconstrução e reestruturação do objeto de estudo constituem o processo de internalização, a partir do qual se reestrutura o próprio modo de pensar dos alunos, assegurando, com isso, seu desenvolvimento.

O texto de Davydov concretiza a proposição de Vygotsky, ao afirmar que a função de uma proposta pedagógica é melhorar o conteúdo e os métodos de ensino e de formação, de modo a exercer uma influência positiva sobre o desenvolvimento de suas habilidades (por exemplo, seus pensamentos, desejos etc.) (idem, p. 32). Esse posicionamento leva a afastar idéias 
pedagógicas correntes em vários países, ora de superpor o desenvolvimento social e emocional ao cognitivo, de sobrepor a atividade prática ao desenvolvimento do pensamento teórico, ou de promover práticas espontaneístas na educação escolar. Para ele, há uma especificidade sócio-histórica dos processos em que as crianças reproduzem as habilidades humanas, de modo a contrapor ao desenvolvimento espontâneo das crianças o papel determinante da educação e do ensino orientado por objetivos (idem, p. 38). Escreve Davydov:

É fato conhecido que o ensino e a educação atingem os objetivos mencionados por meio da direção competente da atividade própria da criança. Quando essa atividade é interpretada abstratamente e, mais ainda, quando o processo do desenvolvimento está desvinculado da educação e do ensino, inevitavelmente surgirá algum tipo de pedocentrismo ou de contraposição entre as necessidades da "natureza" da criança e os requisitos da educação (como tem ocorrido, em numerosas ocasiões, na história do pensamento e da prática pedagógicos). Entretanto, a situação se altera substancialmente se a atividade "própria" da criança, de um lado, é compreendida como algo que surge e se forma no processo da educação e do ensino e, de outro, se é vista no contexto da história da própria infância da criança, determinada pelas tarefas socioeconômicas da sociedade e pelos objetivos e possibilidades da educação e do ensino que a elas correspondem. (1988a, p. 54-55)

Todavia, não se pode extrair daí que a crítica ao espontaneísmo resulte numa imposição de conteúdos. Trata-se de compreender a articulação entre apropriação ativa do patrimônio cultural e o desenvolvimento mental humano.

Dadas estas premissas teóricas, o fato de considerar a natureza e os aspectos específicos da atividade infantil não implica a contraposição entre o desenvolvimento e a educação, mas a introdução, no processo pedagógico, da condição mais importante para a concretização das suas finalidades. Neste caso, segundo as palavras de Rubinstein, o processo pedagógico, como a atividade do professor-educador, forma a personalidade da criança em desenvolvimento na medida em que dirige a atividade da criança, ao invés de substituí-la por uma outra coisa. (idem, p. 55)

Ainda citando Rubinstein, escreve Davydov:

Qualquer tentativa do educador-professor "de introduzir a cognição e as normas morais, ignorando a atividade própria da criança no domínio desse conhecimento e de normas morais, prejudica [...] as próprias bases do seu sadio desenvolvimento mental e moral, o alimento de suas características e qualidades pessoais". (idem, ibidem)

\section{O desenvolvimento do pensamento teórico}

As pesquisas de Davydov tiveram origem na análise crítica da organização do ensino assentada na concepção tradicional de aprendizagem, que leva à formação do pensamento empírico, descritivo e classificatório. Segundo ele, conhecimento que se adquire por métodos transmissivos e de memorização não se converte em ferramenta para lidar com a diversidade de fenômenos e situações que ocorrem na vida prática. Um ensino mais vivo e eficaz para a formação da personalidade deve basear-se no desenvolvimento do pensamento teórico. Trata-se de um processo pelo qual se revela a essência e o desenvolvimento dos objetos de conhecimento e, com isso, a aquisição de métodos e estratégias cognitivas gerais de cada ciência, em função de analisar e resolver problemas e situações concretas da vida prática. O pensamento teórico se forma pelo domínio dos procedimentos lógicos do pensamento, que, pelo seu caráter generalizador, permite sua aplicação em vários âmbitos da aprendizagem.

Como se observa, essa proposta parte da idéiachave de Vygotsky relacionada com o papel do ensino no desenvolvimento das potencialidades intelectuais do ser humano. Davydov não faz pouco caso da escola tradicional, ao contrário, reconhece seus méritos em propiciar aos alunos um certo sistema de conhecimentos e modos de ação na prática cotidiana. Todavia, entende que ela é insuficiente para assimilar o espírito da ciência contemporânea e os princípios 
de uma relação criativa, ativa, e de profundo conteúdo com a realidade (Davydov, 1987), propondo a superação de um tipo de pensamento empírico pelo pensamento teórico.

Para Davydov, o pensamento teórico se caracteriza como o método da ascensão do abstrato para o concreto. Não se trata de pensar apenas abstratamente com um conjunto de proposições fixas, mas de uma instrumentalidade mediante a qual se desenvolve uma relação principal geral que caracteriza o assunto e se descobre como essa relação aparece em muitos problemas específicos. Isto é, de uma relação geral subjacente ao assunto ou problema se deduzem mais relações particulares, tal como ele próprio explicita:

Ao iniciar o domínio de qualquer matéria curricular, os alunos, com a ajuda dos professores, analisam o conteúdo do material curricular e identificam nele a relação geral principal e, ao mesmo tempo, descobrem que esta relação se manifesta em muitas outras relações particulares encontradas nesse determinado material. Ao registrar, por meio de alguma forma referencial, a relação geral principal identificada, os alunos constroem, com isso, uma abstração substantiva do assunto estudado. Continuando a análise do material curricular, eles detectam a vinculação regular dessa relação principal com suas diversas manifestações obtendo, assim, uma generalização substantiva do assunto estudado.

Dessa forma, as crianças utilizam consistentemente a abstração e a generalização substantivas para deduzir (uma vez mais com o auxílio do professor) outras abstrações mais particulares e para uni-las no objeto integral (concreto) estudado. Quando os alunos começam a usar a abstração e a generalização iniciais como meios para deduzir e unir outras abstrações, eles convertem as estruturas mentais iniciais em um conceito, que representa o "núcleo" do assunto estudado. Este "núcleo" serve, posteriormente, às crianças como um princípio geral pelo qual elas podem se orientar em toda a diversidade do material curricular factual que têm que assimilar, em uma forma conceitual, por meio da ascensão do abstrato ao concreto. $(1988 \text { c, p. } 22)^{10}$

${ }^{10}$ Chaiklin interpreta esta proposição da seguinte forma: "Este processo de identificar uma relação geral principal (abstra-
Conforme Davydov, portanto, um ensino baseado na generalização teórica ${ }^{11}$ significa: analisar de maneira autônoma os dados da tarefa; separar neles as conexões essenciais; considerar cada tarefa como uma variante particular daquela que havia sido resolvida inicialmente por meios teóricos (1987, p. 154; 1988b, p. 30, 49). Sobre a base das generalizações teóricas formula alguns princípios do ensino escolar (1987, p. 153):

ção substantiva) e a aplicação para analisar problemas particulares (generalização substantiva) produz um número de abstrações que se integram ou sintetizam em um conceito ou 'núcleo' do assunto. É importante entender que conceito aqui significa um conjunto de procedimentos para deduzir relações particulares da relação abstrata. [...] O propósito da atividade de aprendizagem é ajudar os alunos a dominarem as relações, abstrações, generalizações e sínteses que caracterizam os temas de uma matéria. Este domínio é refletido na sua habilidade para fazer reflexão substantiva, análise e planejamento. A estratégia educacional básica para dar aos alunos a possibilidade para reproduzir pensamento teórico é a de criar tarefas instrucionais cujas soluções requeiram a formação de abstrações substantivas e generalizações sobre as idéias centrais do assunto. Esta aproximação é fundamentada na idéia de Vygotsky da internalização, isto é, alguém aprende o conteúdo da matéria aprendendo os procedimentos pelos quais se trabalham os temas específicos da matéria” (Chaiklin, 2003b).

${ }^{11}$ A Teoria da Generalização tem sido objeto de investigação na psicologia russa desde os anos de 1970. Conforme Lerner e Skatkin: "A formação de conceitos não se reduz à generalização de aspectos idênticos em muitas disciplinas, como se tem feito até hoje na didática. Este tipo de generalização realmente existe no nível do conhecimento empírico, mas ela não permite aprofundar, penetrar na essência da matéria, nos vínculos e relações internas de seus elementos, compreender a matéria em sua origem e desenvolvimento. [...] A generalização não se produz encontrando aspectos semelhantes ou comuns a um grupo de objetos, mas revelando seu fundamento genético geral sob o prisma de seu desenvolvimento. [...] O processo de generalização se manifesta como busca do particular que surgiu da 'célula' inicial, como dedução do fundamento genético geral de todas as disciplinas particulares que compõem o sistema" (1984, p. 80). 
a) A assimilação dos conhecimentos de caráter geral e abstrato precede a familiarização com os conhecimentos mais particulares e concretos; é a partir daqueles que se deduzem estes, correspondendo às exigências da ascensão do abstrato ao concreto.

b) Os conceitos de uma disciplina escolar devem ser assimilados por meio do exame das condições que os originaram e os tornaram essenciais, ou seja, os conceitos não se dão como "conhecimentos já prontos", devendo ser deduzidos a partir do geral e do abstrato.

c) No estudo da origem dos conceitos os alunos devem, antes de tudo, descobrir a conexão geneticamente inicial, geral, que determina o conteúdo e a estrutura do campo de conceitos dados.

d) É necessário reproduzir esta conexão em modelos objetivados, gráficos e simbólicos (literais) que permitam estudar suas propriedades em "forma pura" (por exemplo, a estrutura interna das palavras pode ser representada com a ajuda de esquemas gráficos especiais).

e) Há que se formar nos alunos ações objetivadas que lhes permitam revelar no material de estudo e reproduzir nos modelos as conexões primárias e universais do objeto de estudo, de modo que se garantam as transições mentais do universal para o particular e vice-versa.

f) Os escolares devem passar paulatinamente e no seu devido tempo da realização de ações no plano mental para a realização de ações no plano externo (objetivadas) e vice-versa.

O que se constata nestes princípios é, obviamente, uma clara alusão ao movimento que vai do geral para o particular, encetado pelo pensamento, conforme a lógica dialética, e uma similaridade com o método genético. Com efeito, para Davydov (1988b, p. 24), os componentes de uma tarefa de aprendizagem apresentada pelo professor são: a) a análise do material factual para descobrir nele alguma relação geral que tenha uma conexão regular com as diversas manifes- tações desse material; b) a dedução, em que as crianças deduzem determinadas relações no conteúdo estudado, formando um sistema unificado dessas relações, isto é, o "núcleo" conceitual; c) o domínio do modo geral pelo qual o objeto de estudo é construído, mediante o processo de análise e síntese. ${ }^{12}$ Junto com isso, o método genético refere-se às condições de origem dos conceitos científicos, isto é, aos modos de atividade anteriores aplicados à investigação dos conceitos a serem adquiridos. Para isso, segundo Davydov, é necessário que "os alunos reproduzam o processo atual pelo qual as pessoas criaram conceitos, imagens, valores, normas" (1988b, p. 21-22).

Estas duas estratégias de ensino e aprendizagem representam, talvez, o núcleo mais rico da abordagem teórica de Davydov. Elas buscam superar a co-

${ }^{12}$ Lerner e Skatkin (1984) descrevem como são estruturados os conteúdos das matérias com base na Teoria da Generalização: "Todos os conceitos que fazem parte de uma matéria determinada ou de suas subunidades fundamentais são estudados pelos estudantes por meio da assimilação e domínio das condições materiais que lhe dão origem. Ao estudar as fontes materiais dos conceitos, os alunos descobrem, antes de tudo, o vínculo ou nexo geral de origem genética que determina a estrutura e o conteúdo de todo objeto dos conceitos estudados. Por exemplo, a base geral dos conceitos de matemática são as relações gerais de magnitude; dos conceitos de gramática, a relação entre a forma e o significado da palavra. Este vínculo se reflete ou reproduz em objetos particulares ou modelos, que permitem estudar suas propriedades em forma pura. Por exemplo, as relações gerais das magnitudes se representam ao modo de fórmulas e de estrutura interna da palavra, com o auxílio de esquemas gráficos especiais. Utilizando estas fórmulas e esquemas, os alunos, mediante operações que já dominam, descobrem no novo material este vínculo ou nexo geral. Dessa forma, a assimilação de conhecimentos de caráter geral e abstrato, ou vínculo geral genético, precede a familiarização com conhecimentos mais particulares e concretos. Estes últimos derivam dos primeiros, que constituem seu único fundamento. A estruturação das disciplinas escolares da forma como foi explicada contribui para formar nos escolares um pensamento científico-teórico" (p. 81). 
nhecida dicotomia entre a ênfase nos conteúdos escolares e o desenvolvimento dos processos mentais, ou seja, entre a formação dos conceitos científicos e o desenvolvimento das capacidades do pensar. Nesse sentido, desenvolver nos jovens o pensamento teórico é o processo pelo qual se revela a essência e desenvolvimento dos objetos de conhecimento, e com isso a aquisição de métodos e estratégias cognoscitivas gerais de cada ciência, em função de analisar e resolver problemas cotidianos e profissionais.

A idéia é de que a apropriação dos conceitos (no sentido de "instrumentalidade") requer que o indivíduo reproduza, na sua própria atividade, as capacidades humanas desenvolvidas historicamente. Nessa atividade reprodutiva, "a criança implementa a atividade que é semelhante (não idêntica) à atividade encarnada pelas pessoas nestas capacidades" (1988a, p. 56). Davydov, aqui, cita Leontiev, que escreve que o processo pelo qual a criança se apropria da experiência social "é um processo que tem como resultado a reprodução, pelo indivíduo, de atributos, capacidades e modos de comportamento humanos formados historicamente". E conclui Davydov:

Esta reprodução das capacidades, da atividade, com os instrumentos e conhecimentos, pressupõe que a "criança deve realizar em relação a elas uma atividade prática ou cognitiva que seja proporcional (commensurate) (ainda que não idêntica) à atividade humana incorporada nelas". (idem, p. 23)

É importante assinalar, nessa frase, que trata-se de atividade semelhante, proporcional, mas não idêntica à atividade social-histórica anterior. Ou seja, "quando as crianças aprendem, executam ações mentais comensuráveis às ações pelas quais esses produtos da cultura espiritual tiveram historicamente sua origem" (idem, ibidem). Ainda insistindo na unidade entre apropriação e desenvolvimento, entre o conhecimento e o processo de aquisição do conhecimento. Tal como já assinalamos, "a tarefa fundamental da ciência será a de determinar como o conteúdo do desenvolvimento espiritual da humanidade se transfor- ma nas formas de desenvolvimento espiritual e como a apropriação destas formas pelo indivíduo se transforma no conteúdo do desenvolvimento de sua consciência" (idem, p. 61).

Davydov recrimina no ensino tradicional a transmissão direta aos alunos dos produtos finais da investigação, sem que possam aprender a investigar por si mesmas. Todavia, a questão não está em descartar os conteúdos, mas em estudar os produtos culturais e científicos da humanidade, seguindo o percurso dos processos de investigação, ou seja, reproduzindo o caminho investigativo percorrido para se chegar a esses produtos. O procedimento prático de se realizar essas estratégias são as ações de aprendizagem. Por meio de atividades de abstração e generalização e exercícios escolares, representativos da disciplina, pode-se ensinar às crianças o modo como aprender a manejar seus processos cognitivos.

É clara a vinculação desta idéia - apropriação dos modos de pensar a que as disciplinas científicas recorrem - com duas tendências fortes na pedagogia contemporânea: o método de resolução de problemas e o método do ensino com pesquisa. As ações mentais, segundo Davydov, implicam a resolução de tarefas cognitivas, "que devem ser baseadas em problemas" (1988b, p. 29). Eis como Davydov se posiciona quanto a isso:

\section{[...] podemos entender que a implicação geral e o papel geral da tarefa de aprendizagem no processo de assimila- ção serão os mesmos (a princípio) que os da educação ba- seada em problemas. [...] Observamos que, assim como a aprendizagem, a educação baseada na resolução de proble- mas está internamente associada ao nível teórico da assi- milação do conhecimento e pensamento teórico. (ibidem)}

A idéia do ensino com pesquisa é a de que o professor faça pesquisa enquanto ensina, presente na noção de ensino como "experimentação formativa", em que o professor intervém ativamente por meio de tarefas nos processos mentais das crianças e produz novas formações por meio dessa intervenção. 
A atividade de aprendizagem

e as ações de aprendizagem

Segundo Davydov (1988b, p. 3, 19), a aprendizagem é a atividade principal das crianças em idade escolar, cuja função é propiciar a assimilação das formas de consciência social mais desenvolvida - a ciência, a arte, a moralidade, a lei. As crianças incorporam tanto o conhecimento e as habilidades relacionados com os fundamentos dessas formas de consciência social como também as capacidades construídas historicamente para desenvolver a consciência e o pensamento teóricos. O conteúdo da aprendizagem, em outras palavras, é o conhecimento teórico (usando o termo para significar uma combinação unificada de abstração substancial, generalização e conceitos teóricos).

Ainda conforme Davydov, a base do ensino desenvolvimental é seu conteúdo, do qual derivam os métodos (ou procedimentos) para organizar o ensino:

Esta proposição exemplifica o ponto de vista de Vygotskii e Elkonin. "Para nós, escreveu Elkonin, tem importância fundamental sua idéia (de Vygotskii - VD) de que o ensino realiza seu papel principal no desenvolvimento mental, antes de tudo, por meio do conteúdo do conhecimento a ser assimilado". Concretizando esta proposição, deve-se observar que a natureza desenvolvimental da atividade de aprendizagem no período escolar está vinculada ao fato de que o conteúdo da atividade acadêmica é o conhecimento teórico. (idem, p. 19)

Para que isto ocorra, faz-se necessária uma estrutura da atividade do aprender incluindo uma tarefa de aprendizagem, as ações de aprendizagem e ações de acompanhamento e avaliação, visando à compreensão do objeto de estudo em suas relações. O resultado disso é que os alunos aprendem como pensar teoricamente a respeito de um objeto de estudo e, com isso, formar um conceito teórico apropriado desse objeto para lidar praticamente com ele em situações concretas da vida.
Estas idéias deixam transparecer no pensamento de Davydov o caráter ativo da aprendizagem e, especialmente, a idéia de que a educação escolar constituise numa forma específica de atividade do aluno. A meta da atividade de aprendizagem, incluindo a parceria adulto-criança e crianças-crianças, é a própria aprendizagem, ou seja, o objetivo do ensino é ensinar aos estudantes as habilidades de aprenderem por si mesmos, ou seja, aprender a pensar.

Mas não se trata do "aprender fazendo". Se for enfatizado apenas o caráter concreto da experiência da criança, pouco se conseguirá em termos de desenvolvimento mental. Na expressão de Lipman (1997, p. 73), comentando Davydov, as crianças ficam subnutridas conceitualmente. Com efeito, segundo Davydov (1988c, p. 21), "aos conhecimentos (conceitos) empíricos correspondem ações empíricas (ou formais) e aos conhecimentos (conceitos) teóricos, ações teóricas (ou substanciais)", ou seja, se o ensino nutre a criança somente de conhecimentos empíricos, ela só poderá realizar ações empíricas, sem influir substancialmente no seu desenvolvimento intelectual.

\section{A atividade da aprendizagem e a comunicação}

Esse tópico discute a questão da influência de fatores sociais e culturais, especialmente da comunicação, no desenvolvimento mental. Daniels (2003, p. 9) aponta duas formulações dessa questão no âmbito da Teoria da Atividade: a da interiorização e a da participação. Na orientação que prioriza o processo de internalização, a cultura é fonte do desenvolvimento psíquico à medida que o sujeito realiza uma determinada atividade dirigida à apropriação das capacidades sociais objetivadas em forma de instrumentos, linguagem, obras de arte etc. Essa atividade somente pode ser realizada em comunicação permanente com outras pessoas. Escreve Leontiev:

A comunicação em sua forma externa inicial, como aspecto da atividade conjunta das pessoas, quer dizer, em forma de "comunicação imediata" ou em forma interna, 
interiorizada, conforma [...] as condições indispensáveis e específicas do processo de apropriação, pelos indivíduos, dos êxitos do desenvolvimento histórico da humanidade. (apud Davydov, 2002, p. 57)

Todavia, a comunicação da criança com outras pessoas não está mediatizada pela palavra, mas pelo objeto.

A relação da criança com o objeto está mediatizada inicialmente pelas ações objetais diretas do adulto. [...] As ações da criança estão dirigidas não só ao objeto, mas ao adulto que se encontra presente; por isso a incita à comunicação. Unicamente sobre a base das ações objetais conjuntas com o adulto, a criança vai dominando a linguagem, a comunicação verbal. [...] o exame do processo de transformação da atividade externa conjunta da criança em atividade individual, regulada agora pelas estruturas internas (em outras palavras, o estudo da interiorização da atividade conjunta e das funções psíquicas a ela ligadas), tem uma importância capital para compreender o desenvolvimento psíquico da criança. [...] Mas a criança não pode elaborar e realizar de forma autônoma esta atividade; ela sempre deve ser reestruturada (na criança) pelas pessoas que se encontram em interação e comunicação com ela. [...] Mais à frente, o avanço autônomo e criador do pensamento somente será possível sobre a base da experiência histórica já interiorizada. (idem, p. 58)

Na posição de Davydov, é notória a ênfase ao conhecimento teórico formalmente organizado como base da atividade de aprendizagem, pelo que privilegia mais o "social" e menos o "interativo". Por se basear na natureza teórica da aprendizagem formal, a cultura aparece como algo a ser reproduzido, para o que se torna imprescindível a comunicação entre as pessoas, no sentido de comunicação da experiência social. Ou seja, a interiorização consiste no processo de transformação da atividade coletiva em uma atividade individual. Todavia, em artigo recente, Davydov (1999) destaca o que, para ele, é o núcleo da atividade, ressaltando a comunicação com o outro:
O primeiro componente do núcleo da atividade é a transformação da realidade pelo sujeito coletivo, no curso da atividade coletiva deste indivíduo. [...] Toda atividade coletiva é sempre observada em vários tipos e formas de comunicação material e espiritual. [...] Mas, no processo de comunicação, seja material ou espiritual, surge um princípio básico do qual todos estamos conscientes [...] que é o desempenho coletivo de uma certa atividade pelos indivíduos. [...] O apelo a outras pessoas ocorre na estrutura da atividade coletiva, a atividade que é provida de problemas dos indivíduos ou da equipe. A propósito, o apelo aos outros é a base da qual surgem padrões num coletivo; e os padrões são protótipos culturais. [...] Assim, no núcleo da atividade [...] temos os seguintes pontos: primeiro, a unidade da atividade consciente inclui a natureza coletiva da realização de uma atividade pelo indivíduo coletivo ou uma equipe; em outras palavras, o que chamamos de comunicação prática (metódica), no sentido literal da palavra, não no metafórico. O segundo ponto é o apelo das pessoas umas pelas outras, refletindo sobre suas próprias ações e significados e sobre ações e significados de outras pessoas. O terceiro aspecto do núcleo da atividade está incluído no plano ideal e na imaginação. O quarto, é a atividade consciente individual de uma pessoa individual. (p. 10-11)

Essa citação permite visualizar o caráter coletivo da atividade em geral e, também, da atividade de aprendizagem. Embora nela não apareça a valorização dos aspectos interacionais no ensino, tal como desejariam autores que acentuam na aprendizagem mediada as práticas de participação, fica clara a posição do autor sobre o caráter social e coletivo das aprendizagens, incluindo a atividade conjunta dos alunos.

\section{Conclusão}

O objetivo deste trabalho foi apresentar contribuições da Teoria Histórico-cultural da Atividade para a didática, especialmente para a aprendizagem do pensar e do aprender, com base na obra de V. Davydov. Apresentou-se um esboço do desenvolvimento teórico da Teoria da Atividade desde sua formulação no 
período inicial da psicologia histórico-cultural, bem como as bases teóricas do ensino desenvolvimental formuladas por Davydov, que propiciam o conhecimento teórico da Teoria do Conhecimento e da psicologia marxistas em função de uma teoria de ensino adequada às exigências do mundo contemporâneo.

A Teoria da Atividade de aprendizagem tem como premissa uma afirmação bem pontual de Davydov (1988a, p. 9): "é possível, por meio do ensino e da educação, formar numa pessoa certas capacidades ou qualidades mentais". Uma análise concreta do mundo atual põe-nos ante problemas reais, como as mudanças nos processos de produção e nas demandas de qualificação profissional, o desenvolvimento da microeletrônica, a complexificação dos meios de comunicação e informação, o poder desmedido das mídias na formação das subjetividades, a intelectualização do processo produtivo etc., ainda que reconheçamos a manutenção das características mais marcantes do capitalismo. Há, efetivamente, mudanças no mundo do trabalho que afetam substantivamente a vida dos trabalhadores de todos os níveis, e uma proposta democrática de escola não pode excluí-los de uma formação compatível com essas mudanças. Considerando-se que a educação escolar vincula-se estreitamente ao desenvolvimento cognitivo - entendendo que todos os seres humanos precisam internalizar conhecimentos e desenvolver suas capacidades cognitivas como condição de sua existência social - é desejável esperar dela ações em resposta às demandas postas por essas novas realidades.

Entender, pois, o papel da educação escolar no mundo contemporâneo implica saber que a aquisição de conhecimentos e o desenvolvimento de capacidades mentais dos alunos incluem o conhecimento teórico, juntamente com o desenvolvimento de competências cognitivas complexas. Na introdução à edição espanhola de seu último livro, escreveu Davydov:

Os pedagogos começam a compreender que a tarefa da escola contemporânea não consiste em dar às crianças uma soma de fatos conhecidos, mas em ensiná-las a orientar-se independentemente na informação científica e em qualquer outra. Isto significa que a escola deve ensinar os alunos a pensar, quer dizer, desenvolver ativamente neles os fundamentos do pensamento contemporâneo para o qual é necessário organizar um ensino que impulsione o desenvolvimento. Chamemos esse ensino de "desenvolvimental". (1988d, p. 3)

A Teoria da Atividade presta-se a muitas finalidades, mas especialmente pode auxiliar nas formas de desenvolvimento do pensamento teórico (valendo para os alunos, mas também para os professores); na compreensão da estrutura da atividade docente; na explicitação dos procedimentos e definição de ações e tarefas de aprendizagem para aumentar a eficácia das aprendizagens; na proposição de métodos e procedimentos de estudo e análise das práticas, em especial os contextos socioculturais da atividade, para promover a transformação de espaços institucionais. Nesse sentido, para além das idéias aqui sistematizadas, há que se buscar outros elementos teóricos associados à Teoria da Atividade, para melhor compreensão, por exemplo, das ações subjetivas e seu sentido, das formas de participação guiada nas ações e tarefas de aprendizagem, da pesquisa cultural, das influências socioculturais do contexto na ação orientada para o objeto, dos critérios de análise das práticas em contextos institucionais e sua transformação em direção a objetivos emancipatórios. São apostas muito promissoras para uma visão mais contemporânea e mais plurifacetada do conteúdo da didática, e para o enriquecimento das propostas de currículos e metodologias de formação de professores, uma vez que os objetivos de aprendizagem que esperamos dos alunos devem ser, antes, objetivos da formação de professores.

JOSÉ CARLOS LIBÂNEO, doutor em história e filosofia da educação pela Pontifícia Universidade Católica de São Paulo, é professor aposentado da Universidade Federal de Goiás e professor no Programa de Pós-Graduação em Educação na Universidade Católica de Goiás. Além de numerosos artigos, publicou: Democratização da escola pública: a pedagogia crítico-social dos conteúdos (São Paulo: Loyola, 1985; $19^{a}$ edição, 2003); Didática (São Paulo, Cortez, 1990; $23^{\mathrm{a}}$ edição, 2004); Adeus professor, adeus 
professora? Novas exigências educacionais e profissão docente (São Paulo: Cortez, 1998; $7^{a}$ edição, 2003); Pedagogia e pedagogos, para quê? (São Paulo: Cortez, 1998; $6^{\text {a }}$ edição, 2003); Organização e gestão da escola (Goiânia, Alternativa, 2001; 5 edição, 2004); em co-autoria com Mirza Toschi Seabra e João Ferreira de Oliveira, Educação escolar: políticas, estrutura e organização (São Paulo: Cortez, 2003). Atualmente desenvolve o projeto de pesquisa: As contribuições da psicologia histórico-cultural, da Teoria da Atividade e da pesquisa cultural para o desenvolvimento teórico da didática e das didáticas específicas.E-mail: libaneojc@uol.com.br

\section{Referências bibliográficas}

BELLONI, Maria L. (org.), (2002). A formação na sociedade do espetáculo. São Paulo: Loyola.

CHAIKLIN, Seth, (2003a). Correspondência pessoal com o autor, em 13.07.2003

, (2003b). Developmental teaching in upper-secondary school. Disponível em: <http://www.maro.newmail.ru/>. Acesso em: jul. 2003.

CHAIKLIN, Seth, LAVE, Jean (comps.), (2001). Estudiar las prácticas: perspectivas sobre actividad y contexto. Buenos Aires: Amorrortu.

CHAIKLIN, Seth, HEDEGAARD, Mariane, JENSEN, Uffe Jull (orgs.), (1999). Activity theory and social practice: culturalhistorical approaches. Aarhus (Dinamarca): Aarthus University Press.

COLETIVO DE AUTORES, (2001). Didactica universitária. Universidade de la Habana. Centro de Estúdios para el Perfeccionamiento de la Educación Superior. Anápolis, Go.: Curso de Mestrado. Apostila para uso didático.

DANIELS, Harry, (2003). Vygotsky e a pedagogia. São Paulo: Loyola.

DAVYDOV, Vasili V., (1978). Tipos de generalización en la enseñanza. Havana: Pueblo y Educación.

DAVÍDOV, V. V., (1987). Analisis de los principios didácticos de la escuela tradicional y possibles principios de enseñanza en el futuro proximo. In: SHUARE, Marta. La Psicología evolutiva y pedagogía en la URSS. Antología. Moscu: Editorial Progreso, p. 143-154.

DAVYDOV, V. V., (1988a). Problems of developmental teaching. The experience of theoretical and experimental psychological research. Parte I, cap. 1 - The basic concept of contemporary psychology; cap. 2 - Problems of children's mental development. Soviet Education, New York, aug. , (1988b). Problems of developmental teaching, The experience of theoretical and experimental psychological research. Parte II, cap. 5 - Learning activity in the younger school age period; cap. 6-The mental development of younger school children in the process of learning activity. Soviet Education, New York, sep.

, (1988c). Problems of developmental teaching. The experience of theoretical and experimental psychological research. Parte III, cap. 6 - The mental development of younger school children in the process of learning activity (continuação). Conclusion - appendix. Soviet Education, New York, oct.

DAVIDOV, Vasili, (1988d). La enseñanza escolar y el desarrollo psíquico. Prefácio. Moscu: Editorial Progreso.

, (1999). A new approach to the interpretation of activity structure and content. In: CHAIKLIN, Seth, HEDEGAARD, Mariane, JENSEN, Uffe Jull (orgs.). Activity theory and social practice: cultural-historical approaches. Aarhus (Dinamarca): Aarthus University Press, p. 39-50.

DAVIDOV, Vasili V., (2002). El aporte de A. N. Leontiev al desarrollo de la psicología. In: GOLDER, Mário (org.). Angustia por la utopía. Buenos Aires: Ateneo Vigotskiano de la Argentina, p. 51-60.

DAVIDOV, V.V., RADZIKHOVSKII, L.A., (1988). Vygotsky theory and the activity-oriented approach in psychology. In: WERTSCH, James (org.). Culture, communication and cognition: Vigotskian perspectives. New York: Cambridge University Press, p. 35-65.

DUARTE, Newton, (1996). Educação escolar, teoria do cotidiano e a escola de Vigotski. Campinas: Autores Associados. , (2000). Vigotski e o “aprender a aprender": crítica às apropriações neoliberais e pós-modernas da teoria vigotskiana. Campinas: Autores Associados.

, (2003). Sociedade do conhecimento ou sociedade das ilusões? Campinas: Autores Associados.

ENGESTRÕM, Yrjo, (2002). Non scholae sed vitae discimus: como superar a encapsulação da aprendizagem escolar. In: DANIELS, Harry (org.). Uma introdução a Vygotsky. São Paulo: Loyola, p. 175-197.

GOLDER, Mário (org.), (2002). Angustia por la utopía. Buenos Aires: Ateneo Vigotskiano de la Argentina. 
GONZÁLES REY, F., (2000). El lugar de las emociones en la constitución social de lo psíquico: el aporte de Vigotski. Educação e Sociedade, v. 21, nº 71, p. 132-148, jul.

, (2003). Sujeito e subjetividade. São Paulo: Thomson.

HARGREAVES, Andy, (2001). O ensino como profissão paradoxal. Pátio, Porto Alegre, ano IV, $\mathrm{n}^{\circ}$ 16, p. 13-18, fev.-abr.

HEDEGAARD, Marianne, (2002). A zona de desenvolvimento proximal como base para o ensino. In: DANIELS, Harry (org.). Uma introdução a Vygotsky. São Paulo: Loyola, p. 199-227.

KOZULIN, Alex, (2002). O conceito de atividade na psicologia soviética: Vygotsky, seus discípulos, seus críticos. In: DANIELS, Harry (org.). Uma introdução a Vygotsky. São Paulo: Loyola, p. 111-137.

LEONTIEV, Alexis N., (1983). Actividad, conciencia, personalidad. La Habana: Editorial Pueblo y Educación. , (1992). Uma contribuição à teoria do desenvolvimento da psique infantil. In: VIGOTSKI, L. S., LURIA, A. R., LEONTIEV, A. N. Linguagem, desenvolvimento e aprendizagem. São Paulo: Ícone, p. 59-83.

LERNER, I. Y., SKATKIN, M. N., (1984). Tareas e contenido de la enseñanza geral y politécnica. In: DANILOV, M. A., SKATKIN, M. N. Didáctica de la escuela média. Habana: Editorial Pueblo y Educación, p. 40-97.

LIBÂNEO, José Carlos, (1990). Fundamentos teóricos e práticos do trabalho docente: estudo introdutório sobre pedagogia e didática. Tese de doutorado. Pontifícia Universidade Católica de São Paulo.

LIPMAN, Matthew, (1997). Natasha: diálogos vigotskianos. Porto Alegre: Artes Médicas.

MARAGLIANO, Roberto et al., (1986). Teoria da didática. São Paulo: Cortez Editora; Campinas: Autores Associados.

MORIN, Edgar, (2000). Os sete saberes necessários à educação do futuro. São Paulo: Cortez; Brasília:Unesco.

MOURA, Manoel O., (1998). A educação escolar como ativida$d e$ : olhando a qualidade do ensino a partir da sala de aula. Águas de Lindóia: FEUSP.

, (2000). O educador matemático na coletividade de formação: uma experiência com a escola pública. Tese de livre- docência. Faculdade de Educação da Universidade de São Paulo.

, (2002). A atividade de ensino como ação formadora. In: CASTRO, Amélia D. de, CARVALHO, Ana Maria P. (orgs.). Ensinar a ensinar: didática para a escola fundamental e média. São Paulo: Pioneira Thomson Learning, p. 143162.

, (2003). O educador matemático na coletividade de formação. In: TIBALLI, Elianda F.A., CHAVES, Sandramara M. (orgs.). Concepções e práticas em formação de professores: diferentes olhares. In: Encontro Nacional de Didática e Prática de Ensino, 11., Rio de Janeiro: DP\&A, p. 129-145.

PÉREZ GÓMEZ, Angel I., (1999). La cultura escolar en la sociedad neoliberal. Madrid: Morata.

PIMENTA, Selma G., GHEDIN, Evandro (orgs.), (2002). Professor reflexivo no Brasil: gênese e crítica de um conceito. São Paulo: Cortez.

PORTO, Tania M. E. (org.), (2003). Redes em construção: meios de comunicação e práticas educativas. Araraquara: JM Editora.

SAVIANI, Nereide, (1994). Saber escolar, currículo e didática: problemas da unidade conteúdo-método no processo pedagógico. Campinas: Autores Associados.

SFORNI, Marta S. de Faria, (2003). Aprendizagem conceitual e organização do ensino: contribuições da teoria da atividade. Tese de doutorado. Faculdade de Educação da Universidade de São Paulo.

VYGOTSKY, L. S., (1984). A formação social da mente. São Paulo: Martins Fontes.

ZAMBERLAN, Maria Cristina, (s.d.). A teoria da atividade: agir para transformar algo. (mimeo).

ZINCHENKO, Vladimir P., (1998). A psicologia histórico-social e a teoria psicológica da atividade: retrospectos e prospectos. In: WERTSCH, James V., DEL RÍO, P., ALVAREZ, Amélia (orgs.). Estudos socioculturais da mente. Porto Alegre: Artmed, p. 41-55.

Recebido em outubro de 2003

Aprovado em maio de 2004 


\section{Resumos/Abstracts}

José Carlos Libâneo

\section{A didática e a aprendizagem do pensar e do aprender: a Teoria Histórico-cultural da Atividade e a contribuição de Vasili Davydov} Apresenta algumas contribuições teóricas da pesquisa sobre a psicologia histórico-cultural e a Teoria Históricocultural da Atividade para o pensamento didático. Inicialmente, são sugeridos caminhos para linhas de investigação em didática em relação aos processos de formação de conceitos e desenvolvimento do pensamento. Em seguida, é apresentado um breve histórico da Teoria Histórico-cultural da Atividade e de conceitos básicos a partir de Vygotsky e alguns de seus seguidores. Finalmente, são apresentadas idéias de Vasili Davydov sobre as relações entre ensino e desenvolvimento mental e as bases do ensino desenvolvimental voltado para a formação do pensamento teórico.

Palavras-chave: didática; Vasili Davydov; Teoria Histórico-cultural da Atividade

The didactics and learning of thinking and learning: the Historicalcultural Theory of Activity and the contribution of Vasili Davydov

The article presents some theoretical contributions on research on Historical-cultural psychology and Historical-cultural Theory of Activity for pedagogical thinking. Initially, it suggests paths for lines of investigation in didactics with relation to processes of formation of concepts and development of thinking. It then presents a brief history of the Historical-cultural Theory of Activity and of fundamental concepts based on Vygotsky and some of his followers. Finally, it presents Vasili Davydov's ideas on the relation between teaching and mental development and the bases of developmental teaching directed to the formation of theoretical thinking. Key-words: didactics; Vasili Davydov; Historical-cultural Theory of Activity

Cleide Figueiredo Leitão

Buscando caminhos nos processos de formação/autoformação

A partir da experiência dos Coletivos de Autoformação realizados pela organozação Serviços de Apoio à Pesquisa em Educação (SAPÉ), o texto propõe uma reflexão sobre questões relacionadas à formação de professores de jovens e adultos, considerando as expressões das culturas locais, as singularidades, os saberes cotidianos que são produzidos nas práticas educativas, a diversidade dos sujeitos envolvidos, as histórias de vida e as relações entre o que se é e o que se faz, a articulação possível a partir das diferenças e a produção que pode ser feita no interstício entre diferentes lugares. Sugere como indícios às propostas de formação o incentivo a formas de organização dos professores em cada unidade educativa em um processo de autoformação partilhada, que possibilite a reflexão sobre as suas práticas; e a criação de espaços de trocas e convivências nos quais se possa exercitar a crítica, a criatividade e o aprofundamento das relações entre prática/teoria/prática, favorecendo um exercício autônomo e sistemático dos seus fazeres, saberes, poderes.

Palavras-chave: educação de jovens e adultos; formação de professores; entre-lugares

Searching for paths in processes of formation and self-formation The objective of this article is to reflect upon questions related to the formation of teachers for adult and youth education based on the experience of the Collectives of Self-formation organised by the Service of Support for Research in Education (SAPE), taking into consideration expressions of the local culture, its singularities and the different kinds of daily knowledge that are produced in educational practices, as well as the variety of individuals involved, their life histories and the relations between what we are and what we do and including the possible articulation based on differences and what can be produced in the interstice between different places. It suggests as possible proposals for formation: ways of organising teachers in each educational unit in a shared process of 